Borneo Journal of Science \& Technology, Volume (2), Issue (2), Pages: 54-58

DOI: http://doi.org/10.3570/bjost.2020.2.2-09

e-ISSN: 2672-7439

(C) 2018, UCTS Publisher.

$\begin{array}{lll}\text { Submitted: } 31^{\text {th }} \text { January } 2020 & \text { Accepted: } 05^{\text {th }} \text { May } 2020 & \text { Published: } 31^{\text {th }} \text { July } 2020\end{array}$

\title{
Review on Concrete Beam Reinforced with Basalt Fibre Reinforced Polymer Bars under Incremental of Flexural Load
}

\author{
*Toh Sheng Ngu and Mazizah Ezdiani Mohamad \\ School of Engineering and Technology, University College of Technology Sarawak (UCTS), \\ 96000 Sibu, Sarawak, Malaysia
}

\begin{abstract}
The paper present review on studying the reinforced concrete (RC) beam subjected to flexural load. Basalt fiber reinforced polymer (BFRP) reinforcing bars are used to strengthening the concrete beams. The strengthening of concrete structures is the most challenging problems faced by civil engineers nowadays. Compared to conventional steel reinforcement, BFRP bars have higher tensile strength, life span, corrosion resistance, impervious chloride attack, and electromagnetic transparency. Nevertheless, BFRP bars have low modulus of elasticity over conventional steel. Recently, several researchers had been carried out experimental study on RC beams reinforced with BFRP under four-point load. The flexural load carrying capacity is increasing from ranges $9.8 \%$ to $24 \%$, but none of them has yet been capable of determining the results satisfactorily. This paper presents review on the parameter affect the flexural strength of the RC beams reinforced with BFRP bars under four-point load. The parameter included the dimension of beams, size and arrangement of stirrup, and reinforcement ratio. The response and flexural behavior under flexural load have been thoroughly investigated and discussed. The aim is to provide a better understanding of the behaviour of BFRP strengthened concrete structures and increase flexural strength by using different compressive strength of concrete and reinforcement ratio. Finally, the concluding remark is made along with research gaps and future development of research.
\end{abstract}

Keywords: Basalt Bars, Steel Bars, Reinforced Concrete Beam, Flexural Strength, Crack Pattern

\section{INTRODUCTION}

Concrete is most widely used in the construction industry. This is because concrete is very durable, noncombustible, low maintenance, and available in abundance. Also, concrete is very strong is compression. Therefore, concrete beam has high compressive strength but little tensile strength. This can be observed from the stress block diagram, whereas the concrete below the neutral axis offers no contribution to the strength of the beam as it is subjected to tensile stress, Figure 1. Hence the flexural strength of the RC beam depends on the reinforcement bars to resist the deformation when subjected to load.

Overviews for the building industry, mostly the concrete structures are reinforced by steel reinforcement. Steel reinforcement has good strength, ductility but it will suffer to corrosion when exposed to open environment. In additional, Malaysia is a tropical country with relative high humidity. The average annual humidity within the range of $74 \%$ to $84 \%$ [1]. The effect of high humidity has increased the rate of steel corrosion [2]. Corrosion of steel reduced the crosssection area whereas affects the strength of the steel. To overcome these deficiencies, BFRP bar is an alternative solution to replace conventional steel bars as reinforcement for RC structural due to its non-corrosive characteristic. Without the deterioration of reinforcement have advantages increase the life span of the concrete structures.

Despite the advantages, the BFRP profiles are hindered by some limitations. BFRP is linear elastic and non-yield characteristic material. In the philosophy of reinforced concrete beam design, the main longitudinal reinforcement should exhibit yielding before the concrete crushing [3]. This is to provide ductility and a sign before the failure of the concrete member. Under flexural load, the BFRP reinforced concrete beam will exhibit large deflection and crack wide [4];[5];[6];[7];[8];[9]. This phenomenon is due to the elongation of BFRP bars. Meanwhile, rupture of BFRP bar may occur without any warning and the failure of the concrete member is sudden. Hence, the large deflection and crack wide shows the impending failure of the RC beams. On top of those, the static response and behaviour of RC beam reinforced with BFRP bars, mechanical properties and, previous 
experimental are explained and summarized in this paper.

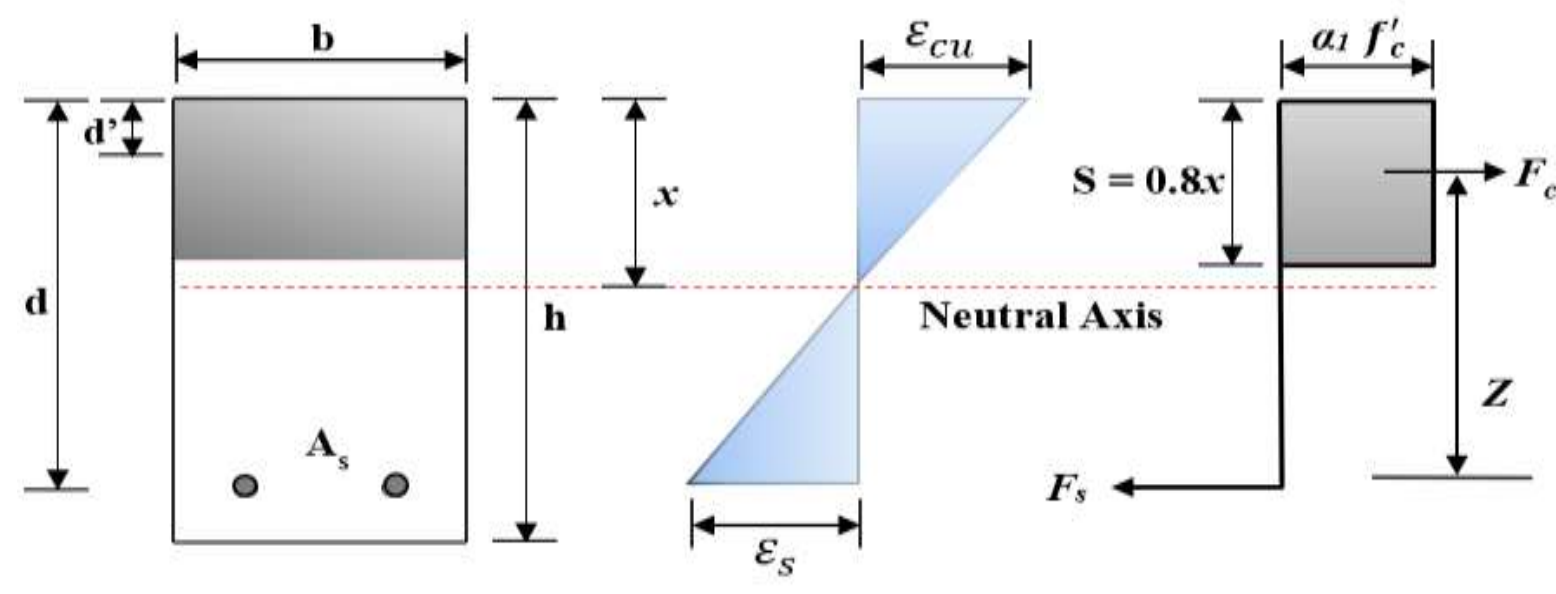

Section

Strains

Stress Block

Figure 1: Section and Stress Block Diagram

\section{METHOD}

This paper provides strength and performance of BFRP concrete beam, flexural crack pattern, and reinforcement ratio through literature studies. The experimental is carried out by using the four-point static load test. The flexural load is increased until the failure of the RC beam. The experimental data of researchers are reported and discussed. Subsequently, review the parameter that influences the load-carrying capacity, deflection, and flexural strength. The results are used to evaluate the efficiency of BFRP bars as internal reinforcement for reinforced concrete beams.

\section{BFRP}

Basalt is magmatic rock, normally in dark-colour. The production process of basalt filament is much simple compared to other FRP filament. First of all, the quarried basalt rock is ruched and washed. Then, the crushed basalt rock is heated under melting temperature in range $1400^{\circ} \mathrm{C}$ to $1500^{\circ} \mathrm{C}$ without adding additives [4, 10]. The molten basalt is extruded through small nozzle to produce basalt fibre filaments. The filaments are bonded with polymeric compound to manufacture BFRP bars with lightweight, high tensile strength, and non-corrosive. Also, Fazio et al. [10] have reported the manufacture of basalt fibre is about a third energy saving compared to the conventional steel reinforcement. Reducing energy demands also reduce the emissions of $\mathrm{CO}_{2}$ into the atmosphere.

In addition, the BFRP bar is about three time tensile strength compared to steel bar [11]. Behaviour of BFRP bar is linear-elastic up until failure. Thus, BFRP bar can achieve higher tensile strength. Buts, BFRP bar will rupture and slitting of fibre when experience tensile force larger than the tensile strength.
Besides, the elastic modulus of BFRP bars is about onequarter of the steel reinforcement (50 GPa compared to $200 \mathrm{GPa}$ ).

Apart from that, like steel reinforcement, BFRP bar can manufacture with bends, Figure 2. But, BFRP bars are non-ductile material and lack of plastic behaviour. Therefore, BFRP bars are difficult to bend onsite. Besides, fib 2007 [12] reported that the bend region will decrease strength up to $40 \%$ to $50 \%$ compare to the straight BFRP bar.

The development of BFRP bar has become a valuable choice to replace steel bar due to its hightemperature [13];[14], environmentally friendly [15], and usable under very low temperature (about $-200^{\circ} \mathrm{C}$ ) [16];[17]. BFRP also perform better in alkaline and acidic environments [18];[19]. Moreover, the challenges in strengthening of the RC beam by using BFRP bars are constructability, building operations, and budget.

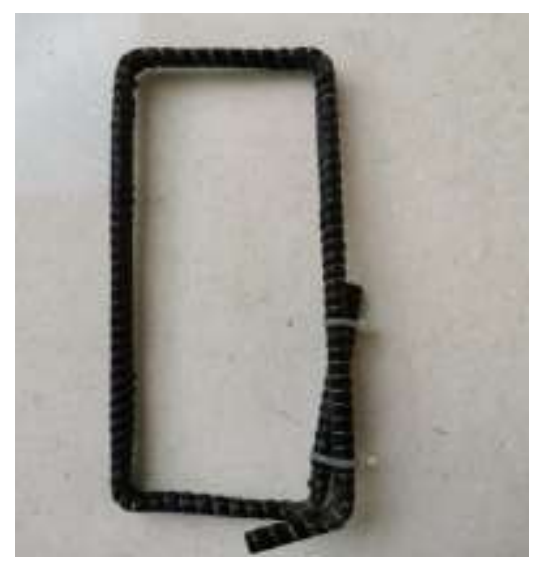

Figure 2: BFRP Bars Fabricated with Bend 


\section{LITERATURE REVIEW}

Urbanski et al. [5] experimentally tested the flexural performance of BFRP beam under four-point load. To perform the tests, three BFRP and three steel RC beams were conducted. All the RC beams with dimension of $80 \mathrm{~mm} \times 140 \mathrm{~mm} \times 1200 \mathrm{~mm}$. The beams were reinforced with $8 \mathrm{~m}$ longitudinal reinforcement and stirrups. The reinforcements were protruded on both sides. This purposed was to measure the slip during the test. Stirrup and longitudinal bar at the middle region of the RC beam was omitted. BFRP concrete beam exhibited crack propagation in middle and slopping crack toward the support. The fact that shear links were omitted, allowed the beam to be subjected to bending. Authors reported that RC beams failure was caused by the shear crack from the support. Also, the authors claimed the crack width was 4 times higher in BFRP beams. The average ultimate load for BFRP beam was $46.7 \mathrm{kN}$ while steel $\mathrm{RC}$ beams were $37.6 \mathrm{kN}$ and were on average $24 \%$ higher. They found the BFRP beams flexural capacity was only $7.8 \mathrm{kNm}$. This was almost two times lower than the theoretical flexural capacity, $14.25 \mathrm{kNm}$.

Rudžinskis et al. [6] investigate the flexural performance of four RC beams under four-point load. One beam as a reference specimen whereas reinforced with steel bars. Three beams were manufactured with different parameter such as bottom basalt bars lapped with steel L bars and not anchored ends. The theoretical load for BFRP reinforced concrete beams was 87.135 $\mathrm{kN}$ while the experimental load was $97.926 \mathrm{kN}, 85.624$ $\mathrm{kN}$, and $80.549 \mathrm{kN}$ respectively. However, the theoretical load for steel RC beam was $45.302 \mathrm{kN}$ while the experimental load was $84.13 \mathrm{kN}$. Also, the theoretical values for deflection were higher than the experimental values. The values were different in range $9.80 \%$ to $15.70 \%$. Furthermore, the experimental result showed that BFRP with the anchored end slightly decreases the RC beams deflection. The authors stated the BFRP beams failure was caused by the BFRP tension bar "snapped" and basalt spiral strands are deboning from longitudinal strands. The BFRP rebar slippage phenomenon was not occurring in this experimental study.

Nandhini et al. [7] conducted research work on RC beam by using steel and BFRP bars. Beam specimens with $7000 \mathrm{~mm}$ in length and $150 \mathrm{~mm}$ in width and height. The beam specimens were tested under flexural load. Three beam specimens were manufactured and reinforced with steel rods, hybrid rods, and BFRP rods, respectively. Ultimate load for steel beam was $97.9 \mathrm{KN}$, BFRP beam was $106.2 \mathrm{KN}$ and the hybrid beam was $111 \mathrm{KN}$. The deflection was relatively small for this large-scale beam specimens. Ultimate deflection for steel, BFRP, and hybrid beam was $1.57 \mathrm{~mm}, 3.57 \mathrm{~mm}$ and $1.63 \mathrm{~mm}$, respectively. In addition, the authors reported that the BFRP beam was 1.13 times higher in strength than steel RC beam.

Elgabbas et al. [8] experimentally investigate the ribbed BFRP bars as reinforcement for RC beams. Eight RC beams were manufactured with cross section $200 \mathrm{~mm} \times 300 \mathrm{~mm} \times 3100 \mathrm{~mm}(\mathrm{~b} \times \mathrm{h} \times \mathrm{L})$. Six BFRP beams were reinforced with $8 \mathrm{~mm}, 12 \mathrm{~mm}$, and $16 \mathrm{~mm}$ bar diameter respectively. Two reference beams were fabricated with $10 \mathrm{~mm}$ and $15 \mathrm{~mm}$ steel bars. To increase the performance of flexural behaviour under load, the shear reinforcements were omitted in the bending moment region. Besides, authors increased BFRP reinforcement ratio and compared to actual concrete strength (balance reinforcement ratio). Furthermore, they found the flexural cracks were vertical, perpendicular toward the load concentred region. As the reinforcement ratio increased, the deflection and crack width were decreased. Buts more small cracks were propagation at middle region towards the supports. Also, the BFRP reinforced concrete beam designed as over reinforcement section will fail due to concrete crushing. Authors reported that the ultimate capacity for $8 \mathrm{~mm}$ BFRP beams increased by $10.3 \%$ when reinforcement ratio increased by $0.3 \%$. Meanwhile, for $12 \mathrm{~mm}$ BFRP beams the ultimate load increase by $43.13 \%$ with two time increase the reinforcement ratio. The $16 \mathrm{~mm}$ BFRP beams increased by $17.67 \%$ compared to reference beams. No signs of slippage of the BFRP longitudinal bars under flexural load.

Sunny et al. [9] carried out research works on BFRP beams under three-point load. Twelve RC beams were fabricated with dimension $150 \mathrm{~mm} \times 200 \mathrm{~mm} \times$ $1000 \mathrm{~mm}(\mathrm{w} \times \mathrm{h} \times \mathrm{L})$. Four groups with three specimens with varying number of reinforcements were tested. Group one (group A) beam specimens reinforced with two 8mm BFRP longitudinal main bars and group B reinforced with three $8 \mathrm{~mm}$ BFRP longitudinal main bars. The similar parameters are applied to steel RC beam (Group C and D). Furthermore, the BFRP beams performed higher ultimate load than steel RC beams. The ultimate load for RC beam reinforced using two and three BFRP bars were $100.33 \mathrm{kN}$ and $110.33 \mathrm{kN}$, respectively. Meanwhile, the ultimate load for RC beam reinforced using two and three steel reinforcements were $86.33 \mathrm{kN}$ and $97 \mathrm{kN}$, respectively. Authors reported the flexural load for BFRP concrete beams reinforced with two tendons bar improved by $16.22 \%$ compared to steel RC beams. Furthermore, for three tendon bars, the BFRP beams flexural load improved by $13.74 \%$ compared to steel RC beams. Also, authors claimed the deflection caused by the flexural load is more in basalt reinforced beam than steel reinforced beams. 


\section{RESEARCH GAP}

Based on the finding and current studies, most of the researchers investigate the behavior of concrete beams by using static loading. In reality, the reinforced beam may subject to kinetic energy or impact energy. Therefore, it is significant to investigate and understand the behavior and performance of BFRP RC beams under impact loading by varying the amount of reinforcement ratio or concrete strength. Meanwhile, this can provide a comparison between dynamic moment capacities and static moment capacities.

Furthermore, experimental study requires extremely stringent quality control and assurance through every process to obtain precise and accurate data. Human error and even deviations in materials can have a significant effect on the results. Hence, the finite element model (FEM) can be performed to test the accuracy of the current experimental results.

The analytical models could be performed to reduce the percentage of the error to predict the flexural strength of BFRP RC beams. Hence, the behavior would be more realistic to an actual beam typically used in practice.

The recommendations for future research areas include:-

1) Investigate the behavior of BFRP RC beams under incremental of static and dynamic load.

2) Investigate the serviceability and structural performance of BFRP RC beams by using different types of concrete, such as normal and high-strength, high-performance, selfconsolidating concrete and light-weight concrete.

3) Investigate various types of fibres including carbon, aramid and basalt fibres into the study to analyse the structural behaviour and response of FRP RC beams

4) Validate the experimental results of BFRP RC beams under static and dynamic load by using finite element modeling. FE simulations can be used to further explore and improve understanding of the behavior of BFRP RC beams.

5) The analytical model developed to describe the flexural strength of BFRP RC beam. The model is to be validated using the experimental results and previous studies.

\section{CONCLUSION}

BFRP is considered as a green material and has illustrated to be a promising material for developing the infrastructure sustainability in RC members. In this paper, experimental studies are reviewed to develop a better understanding of basalt fibre-reinforced polymer reinforcing bars and their structural performance in concrete members. The major conclusions from the literature review are as follow:

1. BFRP bars tend to brittle, with little or no ductility. BFRP bars are low elastic modulus and non-yield characteristic

2. The flexural load for the BFRP beams increased compared to the reference beam or control beam.

3. The over-reinforced BFRP reinforced concrete beam provide more "ductile" response as the beam fail due to concrete crushing rather than rupture of BFRP bars.

4. The crack pattern of BFRP beam was similar to steel RC beam. Buts, the behaviour of crack in BFRP beam was totally different to steel RC beam.

5. Deflection for BFRP beams was twice or three times higher than steel RC beam. As a result, BFRP beam exhibited large deformation and crack width.

6. FRP bars with the anchored end reduced the BFRP beam ultimate deflection

7. Reinforcement ratio increased ultimate load by $10.3 \%$ to $43.13 \%$ for BFRP beam.

8. Omitted the stirrup at the moment region to omit the effect of the factor on flexural behaviour.

\section{ACKNOWLEDGMENT}

This paper was funded by the Civil Engineering Department at University College of Technology Sarawak.

\section{REFERENCE}

[1] Jamaludin, N. \& Izma, N., 2015. Thermal Comfort of Residential Building in Malaysia at Different Micro-Climates. Procedia - Social and Behavioral Sciences, 170, pp.613-623.

[2] Nagata, R., Tachibana, S. and Aso, T. (2020) 'the Influence of Temperature and Humidity on Rust Growth on Weathering Steel', Proceedings of International Structural Engineering and Construction.

[3] American Concrete Institute (ACI) Committee 440. (2015). "Guide for the Design and Construction of Structural Concrete Reinforced with Fiber-Reinforced Polymer (FRP) Bars". American Concrete Institute, ACI 440.1R-15, Farmington Hills, Michigan, USA

[4] Gohnert, M., Van Gool, R. \& Benjamin, M. (2014) 'BFRP reinforced in concrete beams in flexure', The Structural Engineer, pp. 38-43

[5] Urbanski, M., Lapko, A. \& Garbacz, A., 2013. Investigation on Concrete Beams Reinforced with 
Basalt Rebars as an Effective Alternative of Conventional R / C Structures Investigation on Concrete Beams Reinforced with Basalt Rebars as an Effective Alternative of Conventional R / C Structures. Procedia Engineering, 57(June 2016), pp.1183-1191.

[6] Rudžinskis, E., (2017). Flexural behaviour of BFRP rebar reinforced concrete beams. , 10(2), pp.134-170.

[7] Nandhini, M.S. \& Malarvizhi, M.S., (2017). Hybrid Reinforced Concrete Beam Using Steel and BFRP Bars.

[8] Elgabbas, F., Vicent, P., Ahmed, E., \& Benmokrane, B., (2016). Experimental testing of basalt- fi ber-reinforced polymer bars in concrete beams. Composites Part B, 91, pp.205-218.

[9] Sunny, J.C., Prabhakaran, P., (2016). Experimental study on properties of concrete reinforced with basalt bars. , pp.1524-1529.

[10] Fazio, P. De, 2011. Basalt fibra: from earth an ancient material for innovative and modern application. Studi and ricerche, p. 91.

[11] Wu, Z., Wang, X., and Wu, G. (2012). "Advancement of Structural Safety and Sustainability with Basalt Fiber Reinforced Polymers." Proceedings of 6th International Conference on FRP Composites in Civil Engineering (CICE), Rome, Italy, 29 pp.

[12] International Federation for Structural Concrete (FIB). (2007). "FRP Reinforcement in RC Structures." fib Task-Group 9.3, 2007, fib Bulletin 40, pp 1-147.

[13] Brik, V.B. (2003). "Advanced Concept Concrete Using Basalt Fiber/BF Composite Rebar Reinforcement." Final Report for Highway, Innovations Deserving Exploratory Analysis Programs (IDEA), Transportation Research Board of National Academies, Project No. 86
[14] Sim, J., Park, C., and Moon, D. (2005). "Characteristics of Basalt Fiber as a Strengthening Material for Concrete Structures." Journal of Composites Part B: Engineering, 36 (6-7), 504-512

[15] Wu, Z., Wang, X., and Wu, G. (2011). "Advancement of Basalt Fiber Composites Towards Infrastructural." Proceedings of the International Symposium on Innovation \& Sustainability of Structures in Civil Engineering (ISISS2011), Xiamen, China.

[16] Wu, Z., Wang, X., Iwashita, K., Sasaki, T., and Hamaguchi, Y. (2010). "Tensile Fatigue Behaviour of FRP and Hybrid FRP Sheets." Journal of Composites: Part B, 41 (5), 396-402.

[17] Shi, J., Zhu, H., Wu, Z., and Wu, G. (2011a). "Durability of BFRP and Hybrid FRP Sheets underFreeze-Thaw Cycling." Journal of Advanced Materials Research, 163-167, 32973300 .

[18] Shi, J., Zhu, H., Wu, Z., and Wu, G. (2011b). "Effects of Freeze-Thaw Cycles and Sustained Loadon Bond Behavior between FRP Sheet and Concrete Substrate." ACI Special Publication, SP-275, 1-20.

[19] Wei, B., Cao, H., and Song, S. (2010). "Environmental Resistance and Mechanical Performance of Basalt and Glass Fibers." Journal of Materials Science and Engineering: Part A, 527, 4708-4715. 